\title{
Gender differences in fresh vegetable intake from 1979 to 2017 in Finland
}

\author{
Antti Kähäri \\ INVEST Research Flagship Center, University of Turku, Turku, Finland
}

\begin{abstract}
Purpose-Previous research has shown that in contemporary societies, women have a healthier dietary intake than men. However, no research has examined how this gender gap develops over the long term. The present study examined how gender differences in fresh vegetable intake frequency have evolved from 1979 to 2017 in Finland and whether differences are affected by age or educational level.

Design/methodology/approach - The data were derived from annually repeated, nationally representative "Health Behaviour and Health among the Finnish Adult Population" and "Regional Health and Well-being (RHW)" surveys on the health habits of the Finnish population. The dataset is a time series of repeated crosssectional surveys. In total, the data sample comprised 161,996 Finns aged 20-64 years. Descriptive methods and logistic regression were used for the analysis.

Findings - During 1979-2017, the prevalence of daily vegetable intake increased from 12 to $35 \%$ among men and from 18 to $56 \%$ among women. Thus, the magnitude of the gap between genders doubled across the study period. The increased vegetable intake was partly explained by the changing education and age structures of society. Potential explanations and avenues for future research are also discussed. Policy implications depend on whether the findings are interpreted as a case of health differences or health inequality.

Originality/value - This study used a long time series to analyse how gender differences in vegetable intake have evolved in a Nordic welfare state context. It showed that the gap in fresh vegetable intake between men and women has widened.
\end{abstract}

Keywords Gender, Food habits, Vegetable intake, Change

Paper type Research paper

\section{Introduction}

Unhealthy food habits are a leading risk factor for noncommunicable diseases (NCDs), such as cardiovascular disease and type 2 diabetes (World Health Organization, 2003). NCDs cause societal losses in the form of increased healthcare costs and lower productivity. Most contemporary nutritional guidelines recommend that fruits and vegetables comprise half of each plate (Wallace et al., 2020). However, people's consumption of fruits and vegetables fails to meet nutritional recommendations worldwide (Birt et al., 2017; Wallace et al., 2020).

This study aims to elucidate the background of health differences between men and women. In general, mortality rates in men are higher than in women although they report fewer symptoms; consequently, women outlive men (Oksuzyan et al., 2014). However, in societies with high life expectancy, there is only a slight gender difference in the number of healthy life years (Van Oyen et al., 2013). This study analyses healthy food consumption, a behavioural pattern likely to contribute to the health gap between men and women. Existing literature shows that in developed countries, women consume more vegetables and fruits and less red and processed meat than men (Arganini et al., 2012; Wardle et al., 2004). Additionally,

(C) Antti Kähäri. Published by Emerald Publishing Limited. This article is published under the Creative Commons Attribution (CC BY 4.0) licence. Anyone may reproduce, distribute, translate and create derivative works of this article (for both commercial and non-commercial purposes), subject to full attribution to the original publication and authors. The full terms of this licence may be seen at http:// creativecommons.org/licences/by/4.0/legalcode

This research was supported by the Strategic Research Council of the Academy of Finland (decision number 314250).

\section{Gender differences in fresh vegetable intake}

Received 14 September 2021 Revised 11 November 2021 30 November 2021

Accepted 1 December 2021

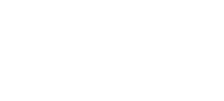

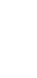


BFJ

124,13

\section{4}

awareness of the health and environmental effects of food consumption has been on the rise, potentially affecting women's food intake more than that of men (Cramer et al., 2017). The Internet has been a key factor in growing awareness, particularly in the recent decade. Research shows that women are more likely to engage in Internet health information seeking compared to men (Manierre, 2015).

However, no research has been conducted to examine how gender differences in healthy food consumption vary over the long term. This study extends the previous literature by analysing gender differences over the long term using data covering 38 years. The question of changing gender differences is especially interesting in the Nordic context, where both gender equality and food habits have developed favourably (Schwab et al., 2017; Holm et al., 2015). The present study considers two societal trends that might affect gender differences in healthy food consumption, namely, education expansion and population ageing. The expansion of higher education has been remarkable, especially among women (Jalovaara et al., 2019). Moreover, Finland is among the most rapidly ageing societies (United Nations, 2019). Both higher education and age are linked to higher fruit and vegetable intake (Kähäri, 2020; Stea et al., 2020). This research answers the following research questions:

$R Q 1$. How has daily vegetable intake changed from 1979 to 2017?

$R Q 2$. How have gender differences in daily vegetable intake changed from 1979 to 2017 ?

$R Q 3$. Are gender differences in daily vegetable intake affected by age and education?

\section{Theoretical background and previous research}

Health behaviour is often divided into health-promoting and health-damaging behaviours. Studies show that, in general, health-damaging behaviours (such as drug use, smoking and risk-taking behaviours) are more common among men, and health-promoting behaviours (such as healthy food habits, regular check-ups and health information seeking) are more common among women (Manierre, 2015; Neve et al., 1996; Pampel, 2001a, b; Rogers et al., 2010; Waldron et al., 2005). Physical exercise is an exception, which is more common among men (Nomaguchi and Bianchi, 2004).

Many studies have examined gender differences in food preferences and intake in childhood, adolescence, adulthood and old age. The vast majority of the studies conducted in developed countries indicate that in all age groups, women have a healthier diet than men (Baker and Wardle, 2003; Cooke and Wardle, 2005; Kiefer et al., 2005; Morse and Driskell, 2009). Several reasons for this have been reported in the literature (Turrell, 1997), including a greater liking for the flavour of healthy food among females than males (Bere et al., 2008). In addition, women tend to be more knowledgeable about dietary recommendations and their health benefits (Davy et al., 2006; Keyes et al., 2011). Moreover, aesthetic concerns-which manifest as greater awareness of body weight and diet - are more prominent among women and are found to be associated with gender differences in diet quality (Wardle et al., 2004, 2006). Some studies indicate that health beliefs and weight consciousness may explain up to $50 \%$ of the gender differences in dietary intake (Westenhoefer, 2005).

While there have been several cross-sectional studies on gender differences in diet, only a few studies have examined how gender differences in healthy food consumption change over time, although within limited time frames. A study conducted in Finland between 1979 and 2002 showed that the difference in daily vegetable intake between men and women increased (Roos et al., 2008). A study conducted in the USA from 1994 to 2005 showed that fruit and vegetable consumption declined slightly, with the decline being greater among men (Michels Blanck et al., 2008). A Norwegian study compared the food habits of children aged 10-12 from 2001 to 2008 and revealed that gender differences remained stable during this period (Hilsen et al., 2011). 
Some insights into how gender differences in food habits evolve can be derived from crossnational comparisons. Prättälä et al. (2007) examined gender differences in meat, fruit and vegetable consumption between Finland and the Baltic countries. They found that gender differences were similar for all the countries, across all age and educational groups, both in rural and urban areas. Consequently, based on the similarity of gender differences across countries and population subgroups, they concluded that the patterns of masculine and feminine food habits seemed to be constant. However, the results tend to vary in studies conducted in different contexts. For instance, Hall et al. (2009) studied the prevalence of low fruit and vegetable intake in 52 low- and middle-income countries. Their study revealed significant gender differences in only 15 countries, of which ten showed a higher prevalence of low fruit and vegetable intake in men and five in women. Therefore, the findings from existing studies indicate that gender differences become more pronounced when resources are more abundant.

In terms of health-damaging behaviour, several researchers have studied whether and how gender differences change over time. For example, many studies have examined gender differences in alcohol use, smoking, marijuana use and accidents (Bratberg et al., 2016; Carliner et al., 2017; Keyes et al., 2011; Pampel, 2001a, b, 2006; Waldron et al., 2005). According to the literature, the gender gap has narrowed in cigarette smoking, but increased in marijuana use. However, existing studies are lacking in research on health-promoting behaviour.

Many studies have suggested that gender roles are a prominent reason for gender differences in diet. Two hypotheses emerge from the premise of changing gender roles and norms. First, the convergence hypothesis predicts decreasing gender differences with an increasing similarity between male and female gender roles. For example, Waldron (1998) links decreasing differences in gender roles to decreasing gender differences in smoking. The convergence dynamic could be expected in a relatively gender-egalitarian context, such as Scandinavia. Therefore, we hypothesised that

H1. Gender differences in daily vegetable intake decreases between 1979 and 2017.

Second, the modified diffusion of innovation hypothesis proposes that the adoption rates of new behaviours differ between genders according to their compatibility with traditional gender roles. Women are expected to adopt behaviours that are compatible with their greater concerns with preserving health more readily than men (Waldron, 1997). Women's predisposition might contribute to their increasing willingness to adopt healthier food habits compared to men, resulting in increasing gender differences. Therefore, we hypothesised that

\section{H2. Gender differences in daily vegetable intake increased between 1979 and 2017.}

Finally, the differential impact of societal trend hypothesis proposes that gender differences in a healthy diet are influenced by societal trends that favour one gender over the other. An example is the expansion of education. Higher education is known to be a strong predictor of healthy food habits (Prättälä et al., 2007). In Finland, women's educational attainment has increased more than that of men over time (Jalovaara et al., 2019). Therefore, in terms of healthy food habits, the expansion of education could benefit women more than men, increasing the gender differences.

Moreover, age contributes to healthy food consumption. Several follow-up studies conducted in Europe revealed that people displayed healthier food habits when transitioning from youth to adulthood and from working life to retirement (Huijbregts et al., 1995; Mikkila et al., 2004; Lake et al., 2006; Plessz et al., 2015). Additionally, cross-sectional studies found that the consumption of fruits, vegetables and fish is more common in older than younger adults (Olsen, 2003; Bojorquez et al., 2015). Since Finland is among the most rapidly ageing societies in the world (United Nations, 2019) and there are more older women than men, we hypothesised that 
BFJ

124,13
H3. Controlling for education and age partly explains the observed gender differences in daily vegetable intake.

\section{Research design}

Subjects

The data for this study were drawn from the Health Behaviour and Health of the Finnish Adult Population (HBHFA) surveys collected annually from 1978 to 2014 and the Regional Health and Well-being surveys (RHW) from 2013 to 2017. The datasets were collected by the Finnish Institute for Health and Welfare.

The HBHFA surveys were postal surveys conducted annually from 1978 to 2014 to monitor short-and long-term changes in health habits and overall health of the Finnish adult population. The study population was Finns aged $15-64$ years with a response rate of $67 \%$ on an average (Helldán and Helakorpi, 2015, p. 10). Even though the response rate has been falling, the time series has generally remained comparable (Helldán and Helakorpi, 2015, p. 9). Although the first HBHFA survey was conducted in 1978, it lacked information on vegetable intake; therefore, this study uses surveys from 1979 onwards.

Since 2014, HBHFA surveys have been incorporated as part of the RHW surveys. These surveys were postal, and Internet surveys were conducted between 2010 and 2017 to monitor regional patterns in adult health, health behaviour and health service use. The study population in the RHW surveys was Finns aged 20 years and over, with response rates of approximately $60-70 \%$ for the oldest age groups and $40 \%$ for women and $30 \%$ for men for the younger age groups. Appropriate weights were used in the analyses to correct for response bias. Only participants aged 20-65 years were included in the analyses, as information for this age bracket was found in both datasets. With the appropriate weights used, the samples are considered nationally representative. Additionally, since RHW surveys generated more responses in the preceding years than HBHFA surveys, only the former were used from 2013 onwards. For the analyses, respondents with missing information on the number of education years $(n=3,094)$ and vegetable intake $(n=3,689)$ were excluded, resulting in an analytical sample of 161,996 .

Dependent variable. The respondents were asked to indicate the frequency and type of food consumption during the preceding week. Fresh vegetable intake was used as the outcome variable. The possible response options were (1) not once, (2) 1-2 days, (3) 3-5 days and (4) 6-7 days. The questions and response options were identical in all surveys. The variable was dichotomised, with "1" indicating fresh vegetable intake on 6-7 days a week and " 0 " indicating less frequent consumption. The dichotomisation was based on the nutritional recommendation that vegetables should be consumed as part of each meal. This categorisation has been successfully used in previous research (Roos et al., 2008). As a sensitivity analysis, the development of the gender difference in fresh vegetable intake was also examined with the other categories of the dependent variable.

Independent variables. The respondents were asked to indicate their gender and year of birth (which was used to calculate their age). Birth year and age were categorised into fiveyear groups to retain sufficient observations per cell. Additionally, the respondents were asked to indicate the number of years they had devoted to full-time education. The education variable was then categorised according to the International Standard Classification of Education (ISCED 2).

Statistical methods. Logistic regression was used as the main statistical method. The dependent variable was daily fresh vegetable intake as a dichotomous variable. In the first model, the independent variables were survey year (in five-year categories) and gender. In the second model, an interaction term for survey year and gender was included to assess the evolution of gender differences over the survey years. Education and age were included as 
control variables in the final model. Graphical representations of the associations were obtained by estimating the marginal means for statistical years and gender from models 1 and 3. All statistical analyses were performed using the StataMP 16.

\section{Results}

Table 1 presents the descriptive statistics of the study population. Findings suggest that, on average, respondents' educational years and age increased, which reflects the changing age and educational structure of the population. The prevalence of daily vegetable intake increased from approximately 15-48\% (Table 1).

Table 2 presents results from the logistic regression models. The coefficients confirm that daily vegetable intake increased during the study period and was more prevalent among women. The interaction term between gender and period revealed that gender differences

\begin{tabular}{|c|c|c|c|c|c|c|}
\hline Year & $\%$ Men & Age group (mode) & Education years & Daily vegetable intake prevalence (\%) & $N$ & \\
\hline 1979 & 51.8 & $30-34$ & 9.6 & 15.1 & 4,561 & \\
\hline 1980 & 51.6 & $30-34$ & 9.8 & 20.2 & 4,321 & \\
\hline 1981 & 51.4 & $30-34$ & 9.7 & 21.4 & 3,761 & \\
\hline 1982 & 52.5 & $30-34$ & 10.1 & 24.5 & 3,680 & \\
\hline 1983 & 49.3 & $30-34$ & 10.2 & 23.0 & 3,669 & \\
\hline 1984 & 45.4 & $35-39$ & 10.5 & 25.5 & 3,443 & \\
\hline 1985 & 47.7 & $35-39$ & 10.7 & 25.3 & 3,061 & \\
\hline 1986 & 46.4 & 35-39 & 10.6 & 24.7 & 3,683 & \\
\hline 1987 & 46.0 & 35-39 & 10.9 & 26.5 & 3,634 & \\
\hline 1988 & 48.6 & 35-39 & 11.0 & 29.9 & 3,538 & \\
\hline 1989 & 47.3 & $40-44$ & 11.1 & 27.9 & 3,523 & \\
\hline 1990 & 47.8 & $40-44$ & 11.3 & 31.8 & 3,476 & \\
\hline 1991 & 46.7 & $40-44$ & 11.5 & 31.0 & 3,465 & \\
\hline 1992 & 46.5 & $40-44$ & 11.5 & 30.3 & 3,350 & \\
\hline 1993 & 46.6 & $40-44$ & 11.9 & 34.9 & 3,120 & \\
\hline 1994 & 47.7 & $45-49$ & 12.0 & 32.9 & 3,136 & \\
\hline 1995 & 46.8 & $45-49$ & 11.9 & 31.8 & 3,288 & \\
\hline 1996 & 46.8 & 45-49 & 12.1 & 32.5 & 3,274 & \\
\hline 1997 & 45.4 & $45-49$ & 12.3 & 36.2 & 3,183 & \\
\hline 1998 & 48.5 & $50-54$ & 12.3 & 40.5 & 3,198 & \\
\hline 1999 & 45.4 & $50-54$ & 12.7 & 39.7 & 3,037 & \\
\hline 2000 & 45.2 & $50-54$ & 12.6 & 36.6 & 3,188 & \\
\hline 2001 & 46.1 & $50-54$ & 12.8 & 36.3 & 3,152 & \\
\hline 2002 & 46.0 & $50-54$ & 12.9 & 36.7 & 2,968 & \\
\hline 2003 & 45.7 & $50-54$ & 13.3 & 35.7 & 3,034 & \\
\hline 2004 & 45.2 & 55-59 & 13.1 & 40.1 & 3,057 & \\
\hline 2005 & 46.6 & 55-59 & 13.2 & 39.2 & 3,028 & \\
\hline 2006 & 45.2 & 55-59 & 13.4 & 41.0 & 2,980 & \\
\hline 2007 & 44.0 & 55-59 & 13.5 & 40.8 & 2,986 & \\
\hline 2008 & 42.9 & 55-59 & 13.6 & 43.0 & 2,969 & \\
\hline 2009 & 43.1 & $60-64$ & 13.8 & 44.0 & 2,725 & \\
\hline 2010 & 44.3 & $60-64$ & 13.7 & 43.5 & 2,596 & \\
\hline 2011 & 43.5 & $60-64$ & 13.9 & 44.4 & 2,605 & \\
\hline 2012 & 43.0 & $60-64$ & 14.1 & 43.6 & 2,411 & Table 1 \\
\hline 2013 & 43.3 & $60-64$ & 14.2 & 40.1 & 30,257 & Demographic \\
\hline 2014 & 43.1 & $60-64$ & 14.3 & 45.5 & 11,471 & characteristics and \\
\hline 2015 & 43.3 & $60-64$ & 14.3 & 42.6 & 11,931 & prevalence of daily \\
\hline 2016 & 41.0 & $60-64$ & 14.6 & 48.8 & 1,345 & vegetable intake in the \\
\hline 2017 & 44.0 & $60-64$ & 14.9 & 47.7 & 2,341 & study samples \\
\hline
\end{tabular}

differences in fresh vegetable intake

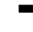




\section{$\mathrm{BFJ}$ 124,13}

\begin{tabular}{|c|c|c|c|}
\hline & Model (1) & Model (2) & Model (3) \\
\hline \multicolumn{4}{|c|}{ Survey year (five-year intervals, ref. 1979) } \\
\hline 1980-1984 & $0.509^{* * * *}(0.0465)$ & $0.541^{* * *}(0.0704)$ & $0.525^{* * * *}(0.0715)$ \\
\hline 1985-1989 & $0.714^{* * *}(0.0464)$ & $0.707^{* * *}(0.0705)$ & $0.619^{* * * *}(0.0717)$ \\
\hline $1990-1994$ & $0.973^{* * * *}(0.0462)$ & $0.933^{* * *}(0.0702)$ & $0.750^{* * * * *}(0.0714)$ \\
\hline 1995-1999 & $1.143^{* * *}(0.0462)$ & $1.047^{* * *}(0.0703)$ & $0.767^{* * * *}(0.0715)$ \\
\hline $2000-2004$ & $1.181^{* * *}(0.0463)$ & $1.028^{* * *}(0.0707)$ & $0.641^{* * * *}(0.0720)$ \\
\hline 2005-2009 & $1.364^{* * *}(0.0463)$ & $1.243^{* * *}(0.0706)$ & $0.789^{* * * *}(0.0720)$ \\
\hline 2010-2014 & $1.380^{* * * *}(0.0440)$ & $1.267^{* * *}(0.0668)$ & $0.710^{* * * *}(0.0683)$ \\
\hline 2015-2017 & $1.460^{* * * *}(0.0461)$ & $1.324^{* * *}(0.0703)$ & $0.735^{* * * *}(0.0719)$ \\
\hline Female (ref. Male) & $0.631^{* * * *}(0.0108)$ & $0.483^{* * *}(0.0865)$ & $0.485^{* * *}(0.0878)$ \\
\hline \multicolumn{4}{|l|}{ Survey year $\times$ gender } \\
\hline $1980-1984 \times$ Female & & $-0.0579(0.0936)$ & $-0.0799(0.0951)$ \\
\hline 1985-1989 × Female & & $0.0149(0.0934)$ & $-0.0135(0.0949)$ \\
\hline 1990-1994 × Female & & $0.0694(0.0931)$ & $0.0311(0.0946)$ \\
\hline 1995-1999 × Female & & $0.164(0.0931)$ & $0.127(0.0947)$ \\
\hline 2000-1904 × Female & & $0.261^{* *}(0.0935)$ & $0.230^{*}(0.0950)$ \\
\hline 2005-1909 × Female & & $0.208^{*}(0.0934)$ & $0.145(0.0950)$ \\
\hline 2010-1914 × Female & & $0.194^{*}(0.0886)$ & $0.135(0.0900)$ \\
\hline 2015-1917 × Female & & $0.232 *(0.0931)$ & $0.181(0.0946)$ \\
\hline \multicolumn{4}{|l|}{ Education (ref. Lowest) } \\
\hline Second lowest & & & $0.558^{* * * *}(0.0175)$ \\
\hline Second highest & & & $0.938^{* * *}(0.0184)$ \\
\hline Highest & & & $1.373^{* * * *}(0.0188)$ \\
\hline \multicolumn{4}{|c|}{ Age group (ref. 20 to 24) } \\
\hline $25-29$ & & & $0.137^{* * * *}(0.0262)$ \\
\hline $30-34$ & & & $0.345^{* * * *}(0.0256)$ \\
\hline 35-39 & & & $0.478^{* * * *}(0.0254)$ \\
\hline 40-44 & & & $0.591^{* * * *}(0.0253)$ \\
\hline $45-49$ & & & $0.687^{* * * *}(0.0251)$ \\
\hline $50-54$ & & & $0.781^{* * * *}(0.0251)$ \\
\hline $55-59$ & & & $0.836^{* * * *}(0.0253)$ \\
\hline $60-64$ & & & $0.860^{* * * *}(0.0257)$ \\
\hline Constant & $-2.696^{* * * *}(0.0463)$ & $-1.980^{* * * *}(0.0652)$ & $-2.906^{* * *}(0.0695)$ \\
\hline$N$ & 161,996 & 161,996 & 161,996 \\
\hline Pseudo $R^{2}$ & 0.038 & 0.038 & 0.072 \\
\hline $\mathrm{BIC}$ & $203,451.8$ & $203,467.2$ & $196,502.0$ \\
\hline \multicolumn{4}{|c|}{$\begin{array}{l}\text { Note(s): Standard errors in parentheses } \\
{ }^{*} p<0.05,{ }^{* * *} p<0.01 \text { and }{ }^{* * * * *} p<0.001\end{array}$} \\
\hline
\end{tabular}

Table 2.

Results of the logistic regression models for daily vegetable intake
58

became significant in the 2000 and 2010s. The final model also included age and education, both of which are positively associated with daily vegetable intake. Daily vegetable intake increased with an increase in education level and age. The addition of these variables made the interaction terms between genders and periods insignificant for the periods after 2005 (Table 2).

Figures 1 and 2 present the estimated marginal means for gender and period from Models 2 and 3 to explain how the gender differences in daily vegetable intake evolved over time and whether the control variables affected this relationship. They show that at each interval, the prevalence of daily vegetable intake was higher among women than among men. The gender difference increased significantly during the period 1979-2004 but remained constant subsequently. Moreover, controlling for changes in education and age structures revealed 


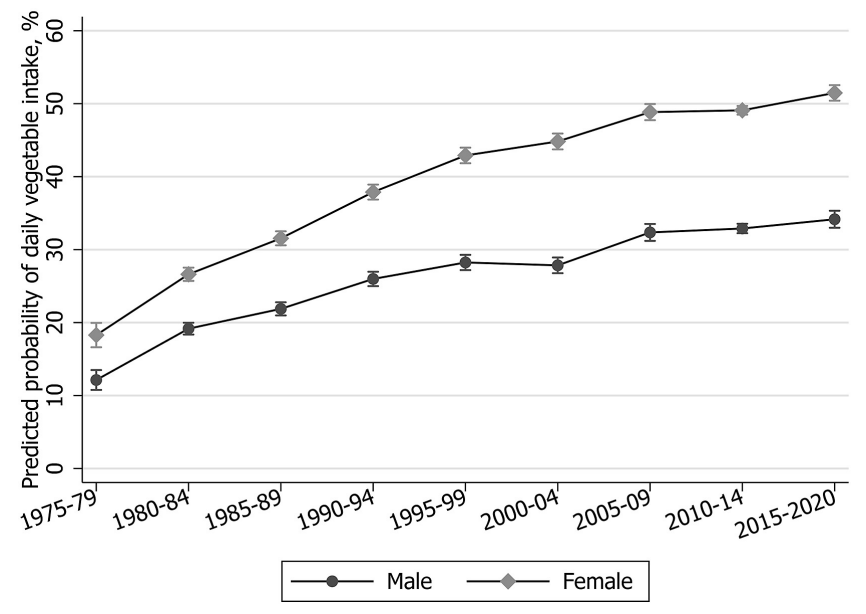

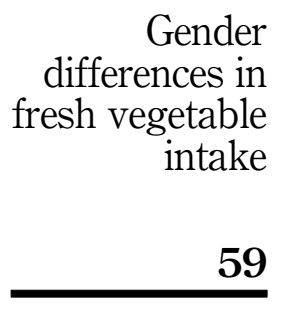

Figure 1. Association between daily vegetable intake and time period for both genders. Estimated marginal means for period and gender from model 2

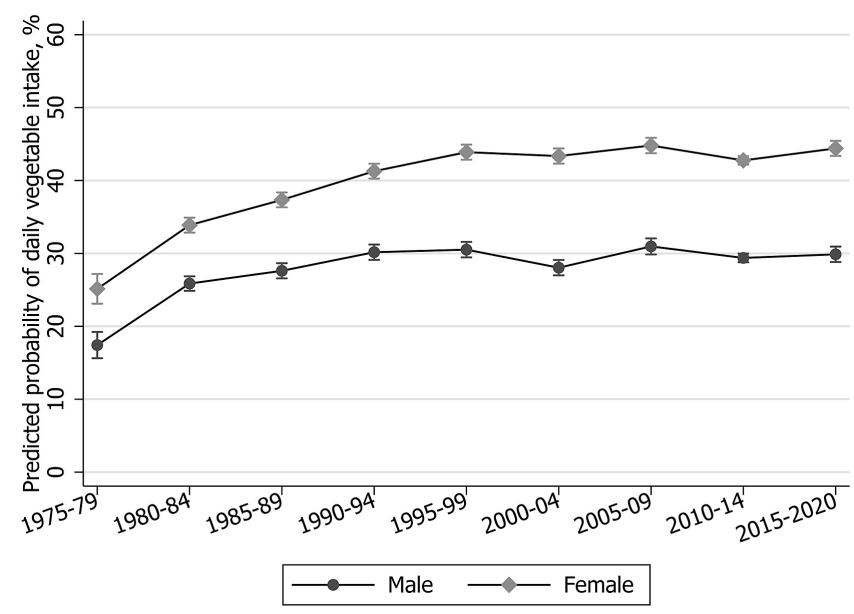

Figure 2. Association between daily vegetable intake and time period for both genders. Estimated marginal means for period and gender from model 3

that vegetable intake and gender differences remained constant in the 2000 and 2010s. Thus, at the population level, education expansion and the ageing population partly explain the increase in vegetable intake.

\section{Sensitivity analysis}

The robustness of the results was tested by examining the temporal changes in the gender difference in fresh vegetable intake using all the categories of the dependent variable. This procedure revealed a more detailed picture about how the gender difference in vegetable intake evolved over time. The respondents in the surveys were asked to indicate on how many days during the preceding week they had eaten fresh vegetables. The most common answer among men was 3-5 times a week, whereas the most common answer for women was 6-7 times a week. During the study period, the prevalence of not eating fresh vegetables at all fell from 10 to $2 \%$ among women and from 16 to $5 \%$ among men. Eating fresh vegetables only on one or two days a week fell from 36 to $15 \%$ among women and from 40 to $24 \%$ among 
BFJ

124,13 men. Eating fresh vegetables on three to five days a week increased from 31 to $36 \%$ among men and fell from 36 to $32 \%$ among women.

\section{Discussion}

This study demonstrated an increase in the prevalence of fresh vegetable intake in Finland from the year 1979-2017, which supports the first hypothesis. The results suggest that, in the 2000 s, this trend was partly explained by the ageing of the population and the expansion of education. In addition to better availability, the increase in daily vegetable intake may also be related to the growing political importance placed on a healthy diet. Finland has an extensive history of health and welfare policies, including the implementation of several nutrition policies and interventions (Popkin, 2006; Puska et al., 2002). For instance, the National Nutrition Council issued official nutritional recommendations, which have been implemented since 1987, emphasising the role of vegetables as a central part of a healthy diet. Another illustrious measure adopted by Finland is the provision of a free daily school meal to children, which every student is entitled to since 1957 (Tikkanen and Urho, 2009). The use of catering services at school or work is associated with healthier food choices (Raulio et al., 2010). These nutritional policies exemplify the preventive nature of the Finnish welfare state.

The gendered analysis of this trend indicated an increase in the gender gap in daily vegetable intake, which supports the second hypothesis, namely, the modified diffusion of innovations hypothesis. It proposes that the adoption rates of new behaviours differ between genders according to their compatibility with traditional gender roles. Women exhibit a greater willingness to adopt behaviours that are consistent with their health concerns compared to men (Waldron, 1997). Consequently, with regard to a healthy diet, women tend to adopt healthier food habits more readily than men, resulting in increasing gender differences. Furthermore, the results suggest that gender equality might not always lead to decreasing gender differences in behaviour.

However, the question as to why women are more willing to adopt a healthy diet than men cannot be answered within the current study design. While the question remains, potential sociological, psychological and biological explanations can be hypothesised, setting the ground for future research. A potential sociological reason for the faster adoption of vegetable consumption in women could be related to macro-level factors. For example, women's greater representation in the fields of health care and catering makes the question of a healthy diet more proximate from an occupational point of view. This could be especially relevant in a welfare state context, which is characterised by "high levels of female labour force participation, along with a high concentration of women in female-typed occupations" (Mandel and Semyonov, 2006, p. 1910).

Additionally, women's greater use of the Internet for social networking and seeking health information could be a social psychological factor contributing to their greater willingness to adopt healthier diets. Previous research has shown that a significant contributor to women's greater adoption of healthier diets can be attributed to aesthetic concerns, which are more prominent among women than men (Wardle et al., 2004; Westenhoefer, 2005). This dynamic could be exacerbated in the era of the internet and social media (Aberg et al., 2020). Over the past few decades, the Internet has established itself as the principal medium for the exchange of health information. Seeking health information on the Internet is more prominent among women than men (Manierre, 2015; Moretti et al., 2012). In addition to official sources, this dissemination of health information is increasing through the use of blogs and social media platforms. Consequently, this has contributed to an increase in the volume and diversity of online health information resources.

The third hypothesis predicted that the ageng population and education expansion would partly explain the gender differences in daily vegetable intake. However, although the 
addition of age and education in the model accounted for an increase in vegetable intake in the 2000s, its effect on gender differences was insignificant. Thus, the results do not support the third hypothesis. It is suggested that trends in vegetable intake might be affected by the changing population structure, as groups that are characterised by higher vegetable intake become more represented over time.

In terms of policy implications, it must be considered whether the gender gap in healthy food consumption is a case of health differences or health inequality, that is, whether the female propensity to consume more vegetables is a matter of personal choice or societal constraints. When addressing the gender gap, a suitable target could be adolescent males, as the basis of food habits is formed early in life (Kelder et al., 1994).

Finally, future research would be wise to ask how the gender gap in healthy food habits varies over time cross-nationally. In addition, future research should utilise multiple indicators of health behaviour and compare changes in male-typical and female-typical health behaviours. Cultural, political and economic explanations for observed gender differences should be explored, for example with macro-level factors through cross-national comparisons. These could not be explored here because of concerns about small sample size and subject anonymity.

\section{Strengths and limitations}

This study was conducted to examine the change in gender differences over a remarkably long time, spanning 38 years. To the best of the author's knowledge, this is the first study to explicitly explore the variation of gender differences in vegetable intake over the long term at the population level. However, a limitation of this study was that vegetable intake was assessed using a food frequency questionnaire. Respondents indicated their subjective assessments of the frequency of food consumption. Some evidence suggests that selfreported dietary measures are subject to social desirability bias, especially among young women and overweight individuals (Hebert et al., 1997; Paalanen et al., 2006). Another limitation that should be stated is that the general trend of falling response rates has happened faster among men than women and also faster among the young age groups than the old age groups (Tolonen et al., 2006). This affects the comparability and representativeness of the results.

\section{Conclusion}

This study examined changes in the association between gender and daily vegetable intake from 1979 to 2017 in a northern welfare state context. Findings revealed that daily vegetable intake is more prevalent among women than men, which is in conformance with previous research conducted in developed nations. Furthermore, it demonstrated an increase in gender differences during the study period. The prevalence of daily vegetable intake increased from 12 to $35 \%$ among men and from 18 to $56 \%$ among women. Thus, the magnitude of the gap between genders doubled across the study period. Increasing vegetable intake was partly explained by the changing education and age structures of society.

\section{References}

Åberg, E., Koivula, A. and Kukkonen, I. (2020), “A feminine burden of perfection? Appearance-related pressures on social networking sites", Telematics and Informatics, Vol. 46 No. 101319, pp. 1-11.

Arganini, C., Saba, A., Comitato, R., Virgili, F. and Turrini, A. (2012), "Gender differences in food choice and dietary intake in modern western societies", Public Health-Social and Behavioral Health, InTech, pp. 83-102. 
BFJ

124,13

62

Baker, A.H. and Wardle, J. (2003), "Sex differences in fruit and vegetable intake in older adults", Appetite, Vol. 40 No. 3, pp. 269-275.

Bere, E., Brug, J. and Klepp, K.-I. (2008), "Why do boys eat less fruit and vegetables than girls?", Public Health Nutrition, Vol. 11 No. 3, pp. 321-325.

Birt, C., Buzeti, T., Grosso, G., Justesen, L., Lachat, C., Lafranconi, A. and Mertanen, E. (2017), Healthy and Sustainable Diets for European Countries, European Public Health Association, Utrecht.

Bojorquez, I., Unikel, C., Cortez, I. and Cerecero, D. (2015), "The social distribution of dietary patterns. Traditional, modern and healthy eating among women in a Latin American city", Appetite, Vol. 92, pp. 43-50.

Bratberg, G.H., Wilsnack, S.C., Wilsnack, R., Håvås Haugland, S., Krokstad, S., Sund, E.R. and Bjørngaard, J.H. (2016), "Gender differences and gender convergence in alcohol use over the past three decades (1984-2008), the HUNT Study, Norway”, BMC Public Health, Vol. 16 No. 1, p. 723.

Carliner, H., Mauro, P.M., Brown, Q.L., Shmulewitz, D., Rahim-Juwel, R., Sarvet, A.L., Wall, M.M., Martins, S.S., Carliner, G. and Hasin, D.S. (2017), "The widening gender gap in marijuana use prevalence in the US during a period of economic change, 2002-2014”, Drug and Alcohol Dependence, Vol. 170, pp. 51-58.

Cooke, L.J. and Wardle, J. (2005), "Age and gender differences in children's food preferences”, British Journal of Nutrition, Vol. 93 No. 5, pp. 741-746.

Cramer, H., Kessler, C.S., Sundberg, T., Leach, M.J., Schumann, D., Adams, J. and Lauche, R. (2017), "Characteristics of Americans choosing vegetarian and vegan diets for health reasons", Journal of Nutrition Education and Behavior, Vol. 49 No. 7, pp. 561-567, e1.

Davy, S.R., Benes, B.A. and Driskell, J.A. (2006), "Sex differences in dieting trends, eating habits, and nutrition beliefs of a group of midwestern college students", Journal of the American Dietetic Association, Vol. 106 No. 10, pp. 1673-1677.

Hall, J.N., Moore, S., Harper, S.B. and Lynch, J.W. (2009), "Global variability in fruit and vegetable consumption”, American Journal of Preventive Medicine, Vol. 36 No. 5, pp. 402-409, e5.

Hebert, J.R., Ma, Y., Clemow, L., Ockene, I.S., Saperia, G., Stanek, E.J., Merriam, P.A. and Ockene, J.K. (1997), "Gender differences in social desirability and social approval bias in dietary self-report", American Journal of Epidemiology, Vol. 146 No. 12, pp. 1046-1055.

Helldán, A. and Helakorpi, S. (2015), Health Behaviour and Health Among the Finnish Adult Population, Spring 2014, THL, Helsinki.

Hilsen, M., van Stralen, M.M., Klepp, K.-I. and Bere, E. (2011), "Changes in 10-12 year old's fruit and vegetable intake in Norway from 2001 to 2008 in relation to gender and socioeconomic status - a comparison of two cross-sectional groups", International Journal of Behavioral Nutrition and Physical Activity, Vol. 8 No. 1, p. 108.

Holm, L., Lauridsen, D.S., Gronow, J., Kahma, N., Kjærnes, U., Lund, T.B., Mäkelä, J. and Niva, M. (2015), "The food we eat in Nordic countries-some changes between 1997 and 2012", in Bergström, K., Jonsson, I.M., Prell, H., Wernersson, I. and Ảberg, H. (Eds.), Mat Är Mer Än Mat: Samhällsvetenskapliga Perspektiv På Mat Och Maltider, Department of Food and Nutrition, and Sport Science, University of Gothenburg, Gothenburg, pp. 227-246.

Huijbregts, P.P., Feskens, E.J., Räsänen, L., Alberti-Fidanza, A., Mutanen, M., Fidanza, F. and Kromhout, D. (1995), "Dietary intake in five ageing cohorts of men in Finland, Italy and The Netherlands", European Journal of Clinical Nutrition, Vol. 49 No. 11, pp. 852-860.

Jalovaara, M., Neyer, G., Andersson, G., Dahlberg, J., Dommermuth, L., Fallesen, P. and Lappegård, T. (2019), "Education, gender, and cohort fertility in the nordic countries", European Journal of Population, Vol. 35 No. 3, pp. 563-586.

Kähäri, A. (2020), "Long-term change in healthy food consumption in Finland during 1985-2016: an age-period-cohort analysis", The International Journal of Sociology of Agriculture and Food, Vol. 26 No. 2, pp. 89-110. 
Kelder, S.H., Perry, C.L., Klepp, K.I. and Lytle, L.L. (1994), "Longitudinal tracking of adolescent smoking, physical activity, and food choice behaviors", American Journal of Public Health, Vol. 84 No. 7, pp. 1121-1126.

Keyes, K.M., Li, G. and Hasin, D.S. (2011), "Birth cohort effects and gender differences in alcohol epidemiology: a review and synthesis", Alcoholism: Clinical and Experimental Research, Vol. 35 No. 12 , pp. 2101-2112.

Kiefer, I., Rathmanner, T. and Kunze, M. (2005), "Eating and dieting differences in men and women", The Journal of Men's Health and Gender, Vol. 2 No. 2, pp. 194-201.

Lake, A.A., Mathers, J.C., Rugg-Gunn, A.J. and Adamson, A.J. (2006), "Longitudinal change in food habits between adolescence (11-12 years) and adulthood (32-33 years): the ASH30 Study", Journal of Public Health, Vol. 28 No. 1, pp. 10-16.

Mandel, H. and Semyonov, M. (2006), "A welfare state paradox: state interventions and women's employment opportunities in 22 countries", American Journal of Sociology, Vol. 111 No. 6, pp. 1910-1949.

Manierre, M.J. (2015), "Gaps in knowledge: tracking and explaining gender differences in health information seeking", Social Science and Medicine, Vol. 128, pp. 151-158.

Michels Blanck, H., Gillespie, C., Kimmons, J.E., Seymour, J.D. and Serdula, M.K. (2008), "Trends in fruit and vegetable consumption among US men and women, 1994-2005", Preventing Chronic Disease, Vol. 5 No. 2, pp. 1-10.

Mikkila, V., Rasanen, L., Raitakari, O.T., Pietinen, P. and Viikari, J. (2004), "Longitudinal changes in diet from childhood into adulthood with respect to risk of cardiovascular diseases: the Cardiovascular Risk in Young Finns Studay", European Journal of Clinical Nutrition; London, Vol. 58 No. 7, pp. 1038-1045.

Moretti, F.A., Oliveira, V.E.D. and Silva, E.M.K.D. (2012), "Access to health information on the internet: a public health issue?”, Revista Da Associação Médica Brasileira, Vol. 58, pp. 650-658.

Morse, K.L. and Driskell, J.A. (2009), "Observed sex differences in fast-food consumption and nutrition self-assessments and beliefs of college students", Nutrition Research, Vol. 29 No. 3, pp. 173-179.

Neve, R.J.M., Drop, M.J., Lemmens, P.H. and Swinkels, H. (1996), "Gender differences in drinking behaviour in The Netherlands: convergence or stability?", Addiction, Vol. 91 No. 3, pp. 357-373.

Nomaguchi, K.M. and Bianchi, S.M. (2004), "Exercise time: gender differences in the effects of marriage, parenthood, and employment", Journal of Marriage and Family, Vol. 66 No. 2, pp. 413-430.

Oksuzyan, A., Shkolnikova, M., Vaupel, J.W., Christensen, K. and Shkolnikov, V.M. (2014), "Sex differences in health and mortality in Moscow and Denmark", European Journal of Epidemiology, Vol. 29 No. 4, pp. 243-252.

Olsen, S.O. (2003), "Understanding the relationship between age and seafood consumption: the mediating role of attitude, health involvement and convenience", Food Quality and Preference, Vol. 14 No. 3, pp. 199-209.

Paalanen, L., Männistö, S., Virtanen, M.J., Knekt, P., Räsänen, L., Montonen, J. and Pietinen, P. (2006), "Validity of a food frequency questionnaire varied by age and body mass index", in Mannisto, S., Virtanen, M.J., Knekt, P., Rasanen, L., Montonen, J. and Pietinen, P. (Eds), Journal of Clinical Epidemiology, Vol. 59, No. 9, pp. 994-1001.

Pampel, F.C. (2001a), "Cigarette diffusion and sex differences in smoking", Journal of Health and Social Behavior, Vol. 42 No. 4, pp. 388-404.

Pampel, F.C. (2001b), "Gender equality and the sex differential in mortality from accidents in high income nations", Population Research and Policy Review, Vol. 20 No. 5, pp. 397-421.

Pampel, F.C. (2006), "Global patterns and determinants of sex differences in smoking", International Journal of Comparative Sociology, Vol. 47 No. 6, pp. 466-487. 
BFJ

124,13

Plessz, M., Guéguen, A., Goldberg, M., Czernichow, S. and Zins, M. (2015), "Ageing, retirement and changes in vegetable consumption in France: findings from the prospective GAZEL cohort", British Journal of Nutrition, Vol. 114 No. 6, pp. 979-987.

Popkin, B.M. (2006), "Global nutrition dynamics: the world is shifting rapidly toward a diet linked with noncommunicable diseases", The American Journal of Clinical Nutrition, Vol. 84 No. 2, pp. 289-298, doi: 10.1093/ajcn/84.2.289.

Prättälä, R., Paalanen, L., Grinberga, D., Helasoja, V., Kasmel, A. and Petkeviciene, J. (2007), “Gender differences in the consumption of meat, fruit and vegetables are similar in Finland and the Baltic countries", The European Journal of Public Health, Vol. 17 No. 5, pp. 520-525.

Puska, P. (2002), "Successful prevention of non-communicable diseases: 25 year experiences with North Karelia Project in Finland”, Public Health Medicine, Vol. 4 No. 1, pp. 5-7.

Raulio, S., Roos, E. and Prättälä, R. (2010), "School and workplace meals promote healthy food habits", Public Health Nutrition, Vol. 13 No. 6A, pp. 987-992, doi: 10.1017/S1368980010001199.

Rogers, R.G., Everett, B.G., Onge, J.M.S. and Krueger, P.M. (2010), "Social, behavioral, and biological factors, and sex differences in mortality", Demography, Vol. 47 No. 3, pp. 555-578, doi: 10.1353/ dem.0.0119.

Roos, E., Talala, K., Laaksonen, M., Helakorpi, S., Rahkonen, O., Uutela, A. and Prättälä, R. (2008), "Trends of socioeconomic differences in daily vegetable consumption, 1979-2002", European Journal of Clinical Nutrition, Vol. 62 No. 7, pp. 823-833.

Schwab, K., Samans, R., Zahidi, S., Leopold, T.A., Ratcheva, V., Hausmann, R. and Tyson, L.D. (2017), The Global Gender Gap Report 2017, Report, World Economic Forum, Geneva, available at: https://apo.org.au/node/208501 (accessed 15 March 2021).

Stea, T.H., Nordheim, O., Bere, E., Stornes, P. and Eikemo, T.A. (2020), "Fruit and vegetable consumption in Europe according to gender, educational attainment and regional affiliation-a cross-sectional study in 21 European countries", PLOS One, Vol. 15 No. 5, e0232521, doi: 10. 1371/journal.pone.0232521.

Tikkanen, I. and Urho, U. (2009), "Free school meals, the plate model and food choices in Finland", British Food Journal, Vol. 111 No. 2, pp. 102-119, doi: 10.1108/00070700910931940.

Tolonen, H., Helakorpi, S., Talala, K., Helasoja, V., Martelin, T. and Prättälä, R. (2006), "25-year trends and socio-demographic differences in response rates: finnish adult health behaviour survey", European Journal of Epidemiology, Vol. 21 No. 6, pp. 409-415.

Turrell, G. (1997), "Determinants of gender differences in dietary behavior", Nutrition Research, Vol. 17 No. 7, pp. 1105-1120.

United Nations (2019), "World population prospects 2019”, available at: https:/population.un.org/wpp/ Download/Standard/Population/ (accessed 31 May 2021).

Van Oyen, H., Nusselder, W., Jagger, C., Kolip, P., Cambois, E. and Robine, J.-M. (2013), "Gender differences in healthy life years within the EU: an exploration of the "health-survival' paradox", International Journal of Public Health, Vol. 58 No. 1, pp. 143-155.

Waldron, I. (1997), "Changing gender roles and gender differences in health behavior", Handbook of Health Behavior Research 1: Personal and Social Determinants, Plenum Press, pp. 303-328.

Waldron, I. (1998), "Gender and health-related behavior", in Gochman, D.S. (Ed.), Health Behavior: Emerging Research Perspectives, Springer US, Boston, MA, pp. 193-208.

Waldron, I., McCloskey, C. and Earle, I. (2005), "Trends in gender differences in accidents mortality: relationships to changing gender roles and other societal trends", Demographic Research, Vol. 13, pp. 415-454.

Wardle, J., Haase, A.M., Steptoe, A., Nillapun, M., Jonwutiwes, K. and Bellisie, F. (2004), "Gender differences in food choice: the contribution of health beliefs and dieting", Annals of Behavioral Medicine, Vol. 27 No. 2, pp. 107-116. 
Wallace, T.C., Bailey, R.L., Blumberg, J.B., Burton-Freeman, B., Chen, C.O., Crowe-White, K.M., Drewnowski, A., Hooshmand, S., Johnson, E., Lewis, R., Murray, R., Shapses, S. and Wang, D.D. (2020), "Fruits, vegetables, and health: a comprehensive narrative, umbrella review of the science and recommendations for enhanced public policy to improve intake", Critical Reviews in Food Science and Nutrition, Vol. 60 No. 13, pp. 2174-2211.

Wardle, J., Haase, A.M. and Steptoe, A. (2006), "Body image and weight control in young adults: international comparisons in university students from 22 countries", International Journal of Obesity, Vol. 30 No. 4, pp. 644-651.

Westenhoefer, J. (2005), “Age and gender dependent profile of food choice”, Diet Diversification and Health Promotion, Vol. 57, pp. 44-51.

World Health Organization (2003), Diet, Nutrition, and the Prevention of Chronic Diseases: Report of a Joint WHO/FAO Expert Consultation, World Health Organization, Geneva.

\section{Corresponding author}

Antti Kähäri can be contacted at: akakah@utu.fi

For instructions on how to order reprints of this article, please visit our website:

www.emeraldgrouppublishing.com/licensing/reprints.htm

Or contact us for further details: permissions@emeraldinsight.com 